\title{
Long-Term Effects of Traditional Chinese Medicine and Hypnotherapy in Patients with Severe Endometriosis - a Retrospective Evaluation
}

\author{
Karin Meissner ${ }^{a, b} \quad$ Barbara Böhling $^{c}$ Annemaria Schweizer-Arau ${ }^{c}$ \\ ${ }^{a}$ Institute of Medical Psychology, Ludwig-Maximilians-University Munich, \\ ${ }^{b}$ Institute of General Practice, Klinikum rechts der Isar, Technical University Munich, \\ ${ }^{c}$ Private Practice, Diessen, Germany
}

\section{Keywords}

Endometriosis · Pain - Acupuncture .

Traditional Chinese medicine $\cdot$ Hypnosis

\section{Summary}

Background: $15 \%$ of patients with severe endometriosis suffer from pain symptoms in spite of pharmacological and surgical treatments. In this retrospective study we aimed to assess the effectiveness of a combined therapy of Traditional Chinese medicine and hypnotherapy (systemic autoregulation therapy, SART) as a novel treatment for endometriosis-associated symptoms. Patients and Methods: 47 patients with severe endometriosis, which were treated with SART, were followed-up by standardized telephone interviews. Follow-up data were compared to baseline assessments. Results: Median follow-up time was 5 years. The median intensity of endometriosis-associated pain had decreased from 8 to 3 points on a $0-10$ point visual analogue scale $(p<0.001) .18$ patients $(38 \%)$ were free of pain, and the number of patients using pain medication had decreased from 38 to 19 (from $81 \%$ to $40 \%$ ). 17 out of the 31 women trying for a pregnancy $(55 \%)$ showed a total of 21 births at follow-up. Exploratory analyses revealed that larger decreases in pain scores correlated significantly with longer treatment durations, suggesting a dose-response relationship. Conclusion: Treatment of endometriosis with a holistic approach of Chinese medicine and hypnotherapy may result in a substantial reduction of pain as well as increased birth rates in patients with therapy-refractory endometriosis. Randomized controlled studies to further investigate the effectiveness of SART are highly warranted.

\author{
Schlüsselwörter \\ Endometriose - Schmerz - Akupunktur . \\ Traditionelle Chinesische Medizin · Hypnose
}

\section{Zusammenfassung}

Hintergrund: $15 \%$ der Patientinnen mit Endometriose leiden trotz pharmakologischer und operativer Behandlung unter starken Schmerzen. In dieser retrospektiven Befragung erfassten wir die Langzeiteffekte einer neuartigen Kombinationstherapie aus traditioneller Chinesischer Medizin und Hypnotherapie (systemische Autoregulationstherapie, SART) bei Patientinnen mit schwerer Endometriose. Patienten und Methoden: 47 Patientinnen mit Endometriose, die sich einer Behandlung mit SART unterzogen hatten, wurden mit standardisierten Telefoninterviews nach ihren Beschwerden und dem weiteren Verlauf ihrer Erkrankung befragt, und die Ergebnisse mit den Ausgangsdaten zu Beginn der Behandlung verglichen. Ergebnisse: Das Follow-up fand im Median 5 Jahre nach Behandlungsende mit SART statt. Die Endometriose-assoziierten Schmerzen waren im Median von 8 auf 3 Punkte gesunken (visuelle Analogskala von 0 bis 10 Punkten; $p<0,001)$. 18 Patientinnen $(38 \%)$ waren schmerzfrei, und die Anzahl von Patientinnen, die Schmerzmedikamente benötigten, ging von 38 auf 19 (von $81 \%$ auf $40 \%$ ) zurück. 17 von den 31 Frauen mit Kinderwunsch (55\%) hatten zur Zeit des Follow-up 21 Kinder zur Welt gebracht. Explorative Analysen ergaben, dass längere Behandlungsdauern mit größeren Schmerzabnahmen assoziiert waren, was eine Dosis-Wirkungsbeziehung nahelegt. Schlussfolgerung: Die Behandlung mit einem ganzheitlichen Therapieansatz aus Chinesischer Medizin und Hypnotherapie konnte die Symptome von Patientinnen mit schwerer Endometriose, die auf konventionelle Therapie nicht ansprach, erheblich verbessern und die Geburtsraten steigern. Randomisierte kontrollierte Studien zur weiteren Untersuchung der Wirksamkeit von SART erscheinen dringend angezeigt.

\begin{tabular}{ll}
\hline KARGER & $\oplus 2010$ S. Karger GmbH, Freiburg \\
Fax +497614520714 & Accessible online at: \\
$\begin{array}{l}\text { Information@Karger.de } \\
\text { www.karger.com }\end{array}$ & www.karger.com/fok
\end{tabular}




\section{Introduction}

Endometriosis is defined as the presence of endometrial-like tissue outside the uterus, which induces a chronic, inflammatory reaction. The condition is predominantly found in women of reproductive age, from all ethnic and social groups. With an incidence of $10-15 \%$, endometriosis is one of the most frequent diseases of females of a reproductive age. Endometriosis is usually associated with severe dysmenorrhea, deep dyspareunia, chronic pelvic pain, ovulation pain, cyclical or perimenstrual symptoms with or without abnormal bleeding, infertility and chronic fatigue [1]. Especially pain can severely impact patients' quality of life [2].

Endometriosis imposes a substantial economic burden on society. According to a recent study, the annual endometriosis costs in the USA in 2002 were approximately 18.8-22 billion USD, and were thus higher than the annual costs for migraine (13-17 billion USD) and Crohn's disease (865 million USD) [1]. Although there are several theories, the pathogenesis of endometriosis is still unclear [3]. Furthermore, according to current knowledge there is no known cure for endometriosis [4]. Treatment options for women with endometriosis-associated pain mainly include surgery and medical treatment [4]. Operative laparoscopy is viewed as first-line treatment for endometriosis-associated pelvic pain, but postoperative recurrence of symptoms is very common [5], and about $50 \%$ of patients who have undergone surgery are re-operated because of continuing symptoms [6].

In addition to surgery and medical treatment, complementary and alternative treatments for endometriosis are applied [4]. These approaches are frequently based on holistic theories, as in the case of traditional Chinese medicine (TCM) or Ayurveda which emphasize emotional, mental, spiritual, and physical aspects of the patient. There are only a few studies that investigate the effects of holistic treatment approaches on endometriosis-associated pain. Two case reports [7] and a pilot study [8] provided preliminary evidence that acupuncture may be an acceptable and safe adjunct treatment for some adolescents with endometriosis-related pelvic pain refractory to standard anti-endometriosis therapies. A recent randomized-controlled trial showed acupuncture to be more efficacious in reducing endometriosis-associated pain and improving quality of life than sham acupuncture [9]. A metaanalysis [10] provided some evidence that Chinese herbal medicine may be superior to conventional treatment in relieving endometriosis-related pain and has fewer side effects. No clinical studies have been published as yet on hypnosis as a treatment for endometriosis-associated pain; only case reports are available [11].

During the past 15 years one of the authors (ASA) has developed a holistic therapy called 'systemic auto-regulation therapy (SART) for an individualized treatment of pain in patients suffering from endometriosis. SART is a combination of both TCM and Western hypnotherapy [12]. Clinical observations of patients during SART suggested substantial and sustained reductions in chronic pelvic pain and associated symptoms. Furthermore, a first retrospective analysis of 36 infertile patients ( 6 with endometriosis) and unsuccessful in vitro fertilisation (IVF) showed that SART increased pregnancy and delivery rates, when compared to the data from the German IVF register [13].

In order to assess the effects of SART on endometriosisassociated symptoms in the long term, we conducted a followup interview with patients who had been treated by SART since 1997.
Table 1. Data collection from patient charts and telephone interviews

\begin{tabular}{lll}
\hline Variable & Patient charts & $\begin{array}{l}\text { Telephone } \\
\text { interviews }\end{array}$ \\
\hline $\begin{array}{l}\text { Patient age } \\
\begin{array}{l}\text { Disease characteristics (e.g., stage and duration of } \\
\quad \text { endometriosis) }\end{array}\end{array}$ & $\mathrm{X}$ & \\
$\begin{array}{l}\text { TCM diagnosis } \\
\begin{array}{l}\text { Treatment characteristics (e.g., start and end of } \\
\text { treatment) }\end{array}\end{array}$ & $\mathrm{X}$ & \\
$\begin{array}{l}\text { Previous surgery for endometriosis } \\
\text { Fulfillment of the wish to have children (if any) }\end{array}$ & $\mathrm{X}$ & \\
$\begin{array}{l}\text { Use of artificial reproduction technologies } \\
\text { Quality, location and duration of endometriosis- }\end{array}$ & $\mathrm{BL}$ & $\mathrm{FU}$ \\
$\quad$ associated pain & $\mathrm{BL}$ & $\mathrm{FU}$ \\
$\begin{array}{l}\text { Severity of endometriosis-associated pain } \\
\text { Use of pain medication }\end{array}$ & & $\mathrm{FU}$ \\
$\begin{array}{l}\text { Severity of dyspareunia and dyschezia } \\
\text { Any other treatments for endometriosis since }\end{array} \quad \mathrm{BL}, \mathrm{FU}$ \\
$\quad$ termination of SART & & $\mathrm{BL}, \mathrm{FU}$ \\
\hline BL = Baseline; FU = Follow-up. & & $\mathrm{BL}, \mathrm{FU}$ \\
\hline
\end{tabular}


Table 2. Case report of a patient suffering from severe endometriosis and treated by SART

\begin{tabular}{|c|c|}
\hline Patient & $\begin{array}{l}\text { 32-year-old woman, married, one child, working as a pharmaceutical } \\
\text { assistant, suffering from severe endometriosis (grade IV) and endometrio- } \\
\text { sis-associated pain for } 8 \text { years. Two surgeries to remove endometriosis } \\
\text { tissue from the abdomen did not improve endometriosis-associated symp- } \\
\text { toms. The third surgery comprised a partial resection of the bowel and } \\
\text { improved pain only transiently for } 6 \text { weeks. GnRH analoga also did not } \\
\text { relieve pain satisfactorily. }\end{array}$ \\
\hline Symptoms & $\begin{array}{l}\text { Stabbing, cramping and tearing pain in the lower abdomen before and } \\
\text { during menstrual bleeding, premenstrual breast tension, constipation, and } \\
\text { dysuria. Pain was most severe during the } 2 \text { weeks before as well as during } \\
\text { menstrual bleeding and required bed rest despite pain medication (ibu- } \\
\text { profen). In addition, the patient suffered from lower back pain, bowel pain } \\
\text { and hemorrhoids, monthly migraine attacks, and permanent throbbing. She } \\
\text { was in a depressive mood and had a very low quality of life. She especially } \\
\text { suffered from the idea of having done everything recommended by doctors } \\
\text { without improvement. }\end{array}$ \\
\hline Findings & $\begin{array}{l}\text { White coated tongue with red spots on the tip and on the sides of the tongue, } \\
\text { dental impressions at the edges, thick venous congestion on the lower part } \\
\text { of the tongue. Her pulse was weak on the middle pulse position and tense } \\
\text { on the renal position of both sides. There was a prominent and painful hot, } \\
\text { venous congestion on MP9 on the left leg. Her conflicts were acute stress } \\
\text { in her professional work and empathic suffering with ill family members. } \\
\text { Another issue was shame for everything that was related to her body. She } \\
\text { had acne since puberty and was ashamed for her stuttering during puberty. }\end{array}$ \\
\hline TCM diagnosis & $\begin{array}{l}\text { Blood stasis, Yang qi and spleen-qi deficency, stagnation of liver-qi with } \\
\text { rising of liver-yang, heat on the layer of the blood. }\end{array}$ \\
\hline Treatment & $\begin{array}{l}\text { Combined hypnotherapy and acupuncture once a month, resolution of } \\
\text { unconscious conflicts with her mother. During hypnotherapy she realized } \\
\text { being torn between the suffering of her mother at one hand and her domi- } \\
\text { nance on the other hand. Permanent acupuncture needles in the ear during } \\
\text { first half year ('frustration point' on the right side, 'point of sorrow' on the } \\
\text { left side). One spoon of Chinese herb granulas ('bu zhong yi qi tang') } \\
3 \text { times a day during the follicular phase; Chinese herb tablets ('unicorn } \\
\text { pearls') during the luteal phase. Chinese fixed herb tablets ('freeing the } \\
\text { moon') during whole cycle; during first } 3 \text { months treatment with fixed } \\
\text { remedies ('clear, empty and cool the menses'). Daily moxibustion of the } \\
\text { lower back and pelvis was performed by the husband during time of lower } \\
\text { back pain and throughout wintertime. The patient had } 25 \text { h of SART } \\
\text { treatment over } 2 \text { years. Then, herbal medication therapy was discontinued } \\
\text { and session frequency was reduced to twice a year. }\end{array}$ \\
\hline Outcome & $\begin{array}{l}\text { Pelvic pain, dysmenorrhea, and premenstrual breast tension had com- } \\
\text { pletely disappeared after } 15 \text { months of treatment. Ibuprofen medication } \\
\text { was no longer necessary and the patient could work during the days of } \\
\text { menstrual bleeding. Dysuria disappeared completely, as did constipation } \\
\text { and bowel pain. The amount of bleeding had increased from small to } \\
\text { normal. Ultrasound controls at the end of treatment showed a reduction of } \\
\text { endometriosis tissue. Migraine headache occurred only during cold winter } \\
\text { days after exposure to sunlight. Lower back pain had disappeared. Patient's } \\
\text { mood and quality of life had improved substantially during the } 2 \text { years of } \\
\text { treatment and she can lead a normal life now. }\end{array}$ \\
\hline
\end{tabular}

\section{Patients and Methods}

Between 1997 and 2008, 64 patients with confirmed endometriosis visited the practice of one of the authors (ASA). These patients were identified by an electronic search for the diagnosis of endometriosis through all record cards of the practice since its opening in 1997. The sample com- prised 6 patients that had also been included in a former investigation on the effectiveness of SART for women with an unfulfilled wish for a child [13]. Most patients came on the recommendation of their treating gynecologist or after conducting a search on the internet. The present retrospective study evaluated the data of 47 patients, who had meanwhile finished therapy, could be contacted by telephone, were treated with SART 
Table 3. Severity and duration of endometriosis-associated pain, and use of pain medication at baseline and at follow-up

\begin{tabular}{|c|c|c|c|}
\hline & $\begin{array}{l}\text { Baseline } \\
(\mathrm{n}=47)\end{array}$ & $\begin{array}{l}\text { Follow-up } \\
(\mathrm{n}=47)\end{array}$ & p-value ${ }^{1}$ \\
\hline Pain severity (scale $0-10$ ), median (range) & $8(2$ to 10$)$ & $3(0$ to 10$)$ & $<0.001$ \\
\hline \multicolumn{4}{|l|}{ Pain duration per menstrual cycle } \\
\hline 0 days, n (\%) & $0(0 \%)$ & $18(38 \%)$ & \\
\hline 1-2 days, n (\%) & $19(40 \%)$ & $19(40 \%)$ & \\
\hline 3-7 days, n (\%) & $15(32 \%)$ & $6(13 \%)$ & \\
\hline$>7$ days, $\mathrm{n}(\%)$ & $13(28 \%)$ & $4(9 \%)$ & \\
\hline Days, median (range) & $3(1$ to 28$)$ & 1 (1 to 28$)$ & $<0.001$ \\
\hline \multicolumn{4}{|l|}{ Use of pain medication } \\
\hline never, n (\%) & $9(19 \%)$ & $28(60 \%)$ & \\
\hline rarely, n (\%) & $3(6 \%)$ & $9(19 \%)$ & \\
\hline sometimes, n (\%) & $7(15 \%)$ & $2(4 \%)$ & \\
\hline very often, n (\%) & $5(11 \%)$ & $3(6 \%)$ & \\
\hline always, n (\%) & $23(49 \%)$ & $5(11 \%)$ & \\
\hline Score $^{2}$, median (range) & $5(1$ to 5$)$ & $1(1$ to 5$)$ & $<0.001$ \\
\hline
\end{tabular}

at least twice, and agreed to participate in the study. 17 patients were excluded ( 10 could not be reached due to move of location, 6 had only a single practice visit, and one refused to participate).

Table 1 summarizes the design of the study. Data were collected from patient charts and telephone interviews. Standardized telephone interviews were carried out in 2009 by one of the authors (BB) who was not involved in the therapy and unknown to the majority of patients. Endometriosis-associated pain, dyspareunia as well as dyschezia were rated on a visual analogue scale (VAS) from 0 (no pain) to 10 (worst imaginable pain). Use of pain medication was determined on a 5-point Likert scale (never, rarely, sometimes, very often, and always). Diagnosis based on criteria of TCM was made by the treating doctor (ASA).

SART uses individualised acupuncture for initiating trance. In addition, an associative technique is used to maintain trance, and most patients see images and memories before their inner eye which are not usually accessible to their consciousness. During emotional destabilization arising in the course of this state (indicated by emotional expressions, such as tears and trembling), needles are inserted into several acupuncture points, or these points are treated with heat (moxibustion) or massage cupping therapy. This frequently induces a sudden improvement in subjective well-being and acute symptoms, such as pain.

Each therapy session usually involved the treatment of more than 6 acupuncture points, and often a permanent acupuncture needle was left in the patient's ear for 2 weeks. If required, and if the costs could be met, patients also received Chinese herb granulates according to the TCM diagnosis, in addition to dietary recommendations. 17 of the 47 patients did not receive any Chinese herbs. The therapy sessions were held as required, typically at intervals of 2-4 weeks. The duration of the treatment was determined not only by sufficient relief of endometriosis-associated symptoms, as some patients continued SART to achieve relief from other medical conditions.

Data were analyzed descriptively by calculating frequencies and percentages for qualitative variables and mean, standard deviation, median, minimum, and maximum for quantitative variables. Pre-post comparisons were made using the Wilcoxon signed rank test for continuous variables, and the sign test for binary variables.

\section{Results}

\section{Patient Characteristics}

At baseline, the median age of the 47 patients included in this retrospective study was 34 years (range, 25-54 years). All patients had severe dysmenorrhea or chronic pelvic pain, in median for 10 years (range, 1-29 years). The diagnosis of endometriosis was confirmed histologically in 46 patients, and ultrasound-determined in 1 patient. According to the American Fertility Society (AFS) score, 4 patients $(8 \%)$ suffered from grade II endometriosis, 6 patients (13\%) from grade III endometriosis, and 37 patients $(79 \%)$ from grade IV endometriosis. 45 patients had already undergone surgical treatment for endometriosis (median, 1; range, 1-10). All patients had a 'xue-' and 'qi-congestion' according to the TCM classification, combined with either a 'kidney-yang' or a 'kidney-yin' deficit, and a 'spleen-qi' deficit. 24 women trying for pregnancy had already made failed attempts with artificial reproduction therapies (between 1 and 8 attempts).

The median length of SART therapy was 15 months (range, 1-90 months). Patients had a median of 12 therapy sessions (range, 2-52). The median follow-up time was 60 months (range, 1-147 months) after the termination of SART. One patient, free of pain after therapy, had entered menopause during the follow-up period. 7 out of the 47 patients discontinued therapy ( 1 due to change of location, 1 due to long distance between home and practice, 2 due to serious life events, and 3 due to lack of efficacy). The data of these patients are included in the analyses.

Table 2 presents a case report describing patient characteristics and symptoms, approach to diagnosis, treatment and outcome in one of the study patients. 


\section{Pain}

At the beginning of the therapy, the 47 patients had rated their endometriosis-associated pain in median at 8 points on a scale from 0 to 10. At follow-up, the intensity of pain had decreased significantly by 5 points in median. 18 patients $(38 \%)$ were no longer in pain, and the number of patients using pain medication had decreased from 38 to 19 (81\% to $40 \%$ ) (table 3 ).

\section{Dyschezia and Dyspareunia}

17 patients had suffered from dyschezia before the treatment. At follow-up, dyschezia had disappeared in 14 patients and remained unchanged in 3 patients (sign test, $\mathrm{p}<0.001$ ). 23 patients had suffered from dyspareunia before the treatment. At follow-up, dyspareunia had vanished in 15 patients, remained unchanged in 8 patients, and had newly appeared in 2 patients (sign test, $\mathrm{p}=0.002$ )

\section{Pregnancy}

Of the 31 patients trying for a pregnancy, 19 (61\%) had become pregnant at least once since the beginning of SART (14 of them spontaneously, 5 after infertility treatment). 5 pregnancies ended with abortion. 17 women $(55 \%)$ showed a total of 21 births, including 13 women with grade IV endometriosis. 5 women with unsuccessful infertility treatment before SART got pregnant spontaneously.

\section{Co-Interventions}

25 patients indicated having used some other kind of treatment for endometriosis-associated symptoms, such as drugs, surgery, or complementary treatment, between baseline and follow-up, and 5 patients did not remember. When only the 17 patients without any co-interventions between baseline and follow-up were included in the analysis, the improvement in endometriosis-associated pain remained significant: Pain severity decreased from a median of 8 points at baseline (range, $2-10$ ) to 1.5 points at follow-up (range, $0-8 ; \mathrm{p}<0.001$ ), and 11 patients $(50 \%)$ were totally free of pain. The duration of pain decreased in all of these women (sign test, $p=0.004$ ), and the number of patients not using pain medication had increased from $8(36 \%)$ at baseline to $18(82 \%)$ at follow-up.

\section{Relationship between Decrease in Pain and Patient Characteristics}

Exploratory correlation analyses revealed that decreases in VAS pain scores (baseline minus posttreatment values) were larger in patients with longer treatment durations (Spearman's $r=0.29, p=0.050)$, larger in patients with shorter time since termination of SART (Spearman's $r=$ $-0.34, p=0.021)$, and smaller in patients with higher age at the beginning of SART (Spearman's $r=-0.30, p=0.041$ ). Decrease in pain scores did not correlate with the duration of disease (Spearman's $r=-0.21, p=0.150$ ). Furthermore, initial pain scores did not correlate with treatment duration (Spearman's $r=-0.17, p=0.263$ ).

\section{Discussion}

The main result of the present study is the demonstration of a substantial decrease in pain intensity, pain duration, and analgesic use after SART in patients with severe endometriosis. Further endometriosis-associated symptoms, such as dyspareunia and defecation problems, were also significantly improved, and more than half of the patients with an unfulfilled wish for a child at baseline had given birth to at least one child by the time of follow-up. Given the median follow-up time of 5 years, these improvements reflect longlasting rather than transient changes. Our retrospective analysis thus suggests that patients with endometriosis who have not found sufficient relief from conventional therapy can benefit from a complex, complementary treatment approach that combines both hypnotherapy and Chinese medicine.

Pain reduction in endometriosis is usually achieved by laparoscopic surgery to remove endometriosis tissue in the abdomen [14] or by hormonal treatment to suppress menstruation. In the present study, the amount of pain reduction at follow-up (63\% reduction of VAS scores at baseline) is comparable to pain reduction induced by conventional treatment. For example, Abbot et al. [15] observed a 33\% reduction of initial VAS scores for dysmenorrhea 6 months after laparoscopic surgery, as compared to a $27 \%$ reduction in the (blinded) diagnostic surgery (placebo) group. 6 months after open repeat laparoscopy, the reduction of VAS scores in the surgery group had increased to $63 \%$. Ling et al. [16] tested a GnRH agonist versus placebo and found a 57\% reduction of VAS pain scores for dysmenorrhea after 12 weeks of true treatment, as compared to a $36 \%$ reduction in the placebo group. Petta et al. [17] compared two hormonal treatments and observed an $82 \%$ reduction of initial VAS scores at 6 months in both groups.

The positive correlation between duration of SART and decrease in pain scores suggests some kind of 'dose-response relationship' in that more sessions of SART go along with larger pain decrease. Furthermore, given the long follow-up time, there is some evidence to assume that improvement by SART may be long lasting. However, some degree of deterioration with time seems to have occurred, as the decrease in pain was smaller in patients with longer follow-up times. It should be noted that the recurrence rate of pain after conventional treatment, such as operative surgery, is rather high (approximately $20-40 \%$ ), and frequently, only hysterectomy combined with bilateral oophorectomy leads to satisfactory pain relief [5]. In the case of hormone therapy, pain usually returns when the treatment is discontinued; imposing problems for patients who want to get pregnant [18]. In the present study, most of the patients experienced significant pain relief without taking hormones, and half of the patients with an unfulfilled wish for a child had delivered one or more babies at follow-up. 
The question as to whether the changes observed in the present study reflect a specific effect of SART or are due to 'unspecific' effects, such as placebo effects, regression to the mean, or spontaneous relief, cannot be answered from the data assessed due to the lack of a control group. However, data from three placebo-controlled studies $[9,15,16]$ suggest that the $63 \%$ improvement of endometriosis-associated pain observed in the present study exceeds the improvement of about $15-30 \%$ in VAS scores that is found in the placebo groups of endometriosis trials. Furthermore, since patients in the present study suffered from pelvic pain for a median of 5 years, the possibility that the observed improvement was due to a spontaneous remission seems rather unlikely. In addition, the 'dose-response relationship' between the number of sessions and the success of SART also argues for a specific treatment effect.

The different components of SART, namely stimulation of acupuncture points by needling, moxibustion, and Tuina massage, as well as individual Chinese herbal teas and hypnotherapy are all by themselves known to affect central pain processing. The effectiveness of acupuncture for chronic pain has been shown in many studies, although sham treatment frequently appears to have a similar effect [19-21]. The effect of Chinese herbal teas on primary dysmenorrhoea was confirmed by a meta-analysis, in which individual treatment with Chinese herbs showed to be superior, in the long run, to other treatments, such as pain medication, acupuncture, and moxibustion [22]. A systematic review of TCM for endometriosis also indicated symptom improvement, but the number of included studies was low [10]. With regard to hypnosis, several studies indicate that pain can be effectively reduced during trance by delivering appropriate suggestions [e.g. 23-26]. It should be noted however that hypnotherapy during SART was not just based on the delivery of positive verbal suggestions during trance. Rather, negative memories and traumatic experiences from early childhood were made accessible to consciousness during trance, and were then modified by using acupuncture, moxibustion, or Tuina massage in an individualized treatment approach. The fact that the success of SART was larger in younger patients probably indicates that memory modulation through hypnotherapy as a form of psychotherapy is easier to obtain in younger patients, when brain plasticity is still high $[27,28]$.

In addition to the combination of these putatively specific components of SART, it seems highly probably that so-called unspecific treatment factors, such as expectations towards treatment, a warm and empathic doctor-patient relationship, attention and compassion delivered by the doctor and the highly individualized treatment approach, also contributed to the improvement observed in the present study. For example, part of the effects of SART may have been due to the expectation of pain relief. Such expectations are known to activate the inner-brain opioid system, resulting in powerful modification of central pain processing [29]. Many of the patients treated with SART were surprised, when pain was effectively relieved during acupuncture. Such positive experiences may have enhanced the expectation of pain relief [30]. Furthermore, the reduction of negative expectations may also have played a role. Several studies have shown that pain-related cortical responses can be induced without any painful stimulus - just because a painful experience is expected [31, 32]. This is the case, when patients fear their next menstruation. As menstruation became less painful during SART, the expectation of a painful menstruation may have decreased, and this decrease of nocebo-like expectations may further have contributed to pain relief.

\section{Limitation of the Results}

The study design was retrospective, and no control group was involved. Pre-post comparisons of endometriosis-associated symptoms allowed a rough estimation of the effectiveness of SART only. Furthermore, time to follow-up varied widely among patients, and no assessment was performed immediately at the end of treatment. The data are subjective, and perhaps some of the patients answered more positively than they felt. We tried to avoid this by having an author unknown to the majority of patients conduct the follow-up interviews. However, given the shortcomings of the present study, the results have to be regarded preliminary in nature.

\section{Conclusion}

Results suggest that a holistic approach of Chinese medicine and hypnotherapy might result in relevant improvements in patients with severe, long-lasting and treatment-refractory endometriosis. Controlled randomized trials to further investigate the effectiveness of this complementary treatment approach for endometriosis are highly warranted.

\section{Acknowledgements}

The authors would like to thank all patients for their assurance and the opening of their feelings during therapy. We gratefully acknowledge Martina Kron and Silvia Sanders for performing a first data analysis, and Klaus Linde for commenting on drafts of the manuscript.

\section{Disclosure Statement}

The authors declare that they have no competing interest. 


\section{References}

1 Simoens S, Hummelshoj L, D'Hooghe T: Endometriosis: cost estimates and methodological perspective. Hum Reprod Update 2007;13:395-404.

2 Brandes I: [Quality of life of patients with endometriosis]. Geburtsh Frauenheilk 2007;67:1227-1231.

3 Baldi A, Campioni M, Signorile PG: Endometriosis: pathogenesis, diagnosis, therapy and association with cancer (review). Oncol Rep 2008;19:843846.

4 Rogers PA, D'Hooghe TM, Fazleabas A, Gargett CE, Giudice LC, Montgomery GW, Rombauts L, Salamonsen LA, Zondervan KT: Priorities for endometriosis research: recommendations from an international consensus workshop. Reprod Sci 2009;16:335-346.

5 Vercellini P, Barbara G, Abbiati A, Somigliana E, Vigano P, Fedele L: Repetitive surgery for recurrent symptomatic endometriosis: what to do? Eur J Obstet Gynecol Reprod Biol 2009;146:15-21.

6 Cheong Y, Tay P, Luk F, Gan HC, Li TC, Cooke I: Laparoscopic surgery for endometriosis: How often do we need to re-operate? J Obstet Gynaecol 2008;28:82-85.

7 Highfield ES, Laufer MR, Schnyer RN, Kerr CE, Thomas P, Wayne PM: Adolescent endometriosisrelated pelvic pain treated with acupuncture: two case reports. J Altern Complement Med 2006;12: 317-322.

8 Wayne PM, Kerr CE, Schnyer RN, Legedza AT, Savetsky-German J, Shields MH, Buring JE, Davis RB, Conboy LA, Highfield E, Parton B, Thomas P, Laufer MR: Japanese-style acupuncture for endometriosis-related pelvic pain in adolescents and young women: results of a randomized sham-controlled trial. J Pediatr Adolesc Gynecol 2008;21:247-257.

9 Rubi-Klein K, Kucera-Sliutz E, Nissel H, Bijak M, Stockenhuber D, Fink M, Wolkenstein E: Is acupuncture in addition to conventional medicine effective as pain treatment for endometriosis? A randomised controlled cross-over trial. Eur J Obstet Gynecol Reprod Biol 2010, 153:90-93.

10 Flower A, Liu JP, Chen S, Lewith G, Little P: Chinese herbal medicine for endometriosis. Cochrane Database Syst Rev 2009:CD006568.

11 Tzafettas J: Painful menstruation. Pediatr Endocrinol Rev 2006;3(suppl 1):160-163.
12 Schweizer-Arau A, Mack R: [Treatment of symptoms related to endometriosis with Systemic $\mathrm{Au}$ toregulation Therapy (SART) - two case reports]. Geburtsh Frauenheilk 2008;68:1-8.

13 Schweizer-Arau A: [Effects of systemic autoregulation therapy (SART) and subsequent IVF/ICSI treatment on the pregnancy rate and baby-takehome rate]. Geburtsh Frauenheilk 2007;67:1-6.

14 Vercellini P, Trespidi L, Colombo A, Vendola N, Marchini M, Crosignani PG: A gonadotropinreleasing hormone agonist versus a low-dose oral contraceptive for pelvic pain associated with endometriosis. Fertil Steril 1993;60:75-79.

15 Abbott J, Hawe J, Hunter D, Holmes M, Finn P, Garry R: Laparoscopic excision of endometriosis: a randomized, placebo-controlled trial. Fertil Steril 2004;82:878-884.

16 Ling FW: Randomized controlled trial of depot leuprolide in patients with chronic pelvic pain and clinically suspected endometriosis. Pelvic Pain Study Group. Obstet Gynecol 1999;93:51-58.

17 Petta CA, Ferriani RA, Abrao MS, Hassan D, Rosa ESJC, Podgaec S, Bahamondes L: Randomized clinical trial of a levonorgestrel-releasing intrauterine system and a depot GnRH analogue for the treatment of chronic pelvic pain in women with endometriosis. Hum Reprod 2005;20:1993-1998.

18 Jones G, Jenkinson C, Kennedy S: The impact of endometriosis upon quality of life: a qualitative analysis. J Psychosom Obstet Gynaecol 2004;25: 123-133.

19 Linde K, Allais G, Brinkhaus B, Manheimer E, Vickers A, White AR: Acupuncture for migraine prophylaxis. Cochrane Database Syst Rev 2009: CD001218.

20 Madsen MV, Gotzsche PC, Hrobjartsson A: Acupuncture treatment for pain: systematic review of randomised clinical trials with acupuncture, placebo acupuncture, and no acupuncture groups. BMJ 2009;338:a3115.

21 Linde K, Streng A, Jurgens S, Hoppe A, Brinkhaus B, Witt C, Wagenpfeil S, Pfaffenrath V, Hammes MG, Weidenhammer W, Willich SN, Melchart D: Acupuncture for patients with migraine: a randomized controlled trial. JAMA 2005;293:2118-2125.
22 Zhu X, Proctor M, Bensoussan A, Wu E, Smith CA: Chinese herbal medicine for primary dysmenorrhoea. Cochrane Database Syst Rev 2008: CD005288.

23 Rainville P, Carrier B, Hofbauer RK, Bushnell MC, Duncan GH: Dissociation of sensory and affective dimensions of pain using hypnotic modulation. Pain 1999;82:159-171.

24 Rainville P, Duncan GH, Price DD, Carrier B Bushnell MC: Pain affect encoded in human anterior cingulate but not somatosensory cortex. Science 1997;277:968-971.

25 Vanhaudenhuyse A, Boly M, Balteau E, Schnakers C, Moonen G, Luxen A, Lamy M, Degueldre C, Brichant JF, Maquet P, Laureys S, Faymonville ME: Pain and non-pain processing during hypnosis: a thulium-YAG event-related fMRI study. Neuroimage 2009;47:1047-1054.

26 Faymonville ME, Laureys S, Degueldre C, Del Fiore G, Luxen A, Franck G, Lamy M, Maquet P: Neural mechanisms of antinociceptive effects of hypnosis. Anesthesiology 2000;92:1257-1267.

27 Liggan DY, Kay J: Some neurobiological aspects of psychotherapy. A review. J Psychother Pract Res 1999;8:103-114.

28 Muller-Dahlhaus JF, Orekhov Y, Liu Y, Ziemann $\mathrm{U}$ : Interindividual variability and age-dependency of motor cortical plasticity induced by paired associative stimulation. Exp Brain Res 2008;187:467475.

29 Price DD, Finniss DG, Benedetti F: A comprehensive review of the placebo effect: recent advances and current thought. Annu Rev Psychol 2008;59: 565-590.

30 Colloca L, Sigaudo M, Benedetti F: The role of learning in nocebo and placebo effects. Pain 2008; 136:211-218.

31 Colloca L, Benedetti F: Nocebo hyperalgesia: how anxiety is turned into pain. Curr Opin Anaesthesiol 2007;20:435-439.

32 Koyama T, McHaffie JG, Laurienti PJ, Coghill RC: The subjective experience of pain: where expectations become reality. Proc Natl Acad Sci U S A 2005;102:12950-12955. 